\title{
¿Quitarse de pleitos? Litigiosidad mercantil y práctica arbitral en la Carrera de Indias a finales del siglo XVI
}

\author{
por \\ Ana Belem Fernández Castro ${ }^{1}$ \\ Paris 1, Panthéon-Sorbonne
}

El arbitraje se ha considerado como la vía idónea para resolver disputas mercantiles. Sin embargo, los pleitos de la Casa de la Contratación de Sevilla evidencian las dificultades a las que se enfrentaba esta práctica debido a la carencia de los árbitros de poderes coercitivos para exigir el cumplimiento de los laudos. Esto significaba que la ejecución de los mismos precisó de la intervención de los tribunales, lo cual desvirtúa el propósito del arbitraje como solución extrajudicial, simplificada y económica.

Palabras Clave: arbitraje; Casa de la Contratación; litigiosidad mercantil; justicia ordinaria; comercio de larga distancia.

Cómo citar este artículo / Citation: Fernández Castro, Ana Belem, «¿Quitarse de pleitos? Litigiosidad mercantil y práctica arbitral en la Carrera de Indias a finales del siglo XVI», Revista de Indias, LXXIX/275 (Madrid, 2019): 51-77. https://doi.org/10.3989/revindias.2019.002.

\section{INTRODUCCIÓN}

Cada vez son más los historiadores que confirman el uso que los mercaderes hacían de los diferentes recursos jurisdiccionales a su disposición para resolver los conflictos derivados de sus negocios 2 . Desde la justicia mercantil de los consulados, hasta las jurisdicciones civiles y eclesiásticas de las localidades en que se encontraban, los mercaderes — naturales y extranjeros por

\footnotetext{
1 Ana.Fernandez@eui.eu, ORCID iD: https://orcid.org/0000-0003-2739-4970.

2 Greif, 1997: 239-266. Ogilvie, 2011: 296. Gelderblom, 2013: 102-140.
} 
igual - aprovechaban cualquier instrumento jurisdiccional que pudiera rendir algún beneficio a sus intereses económicos. El arbitraje era una de esas posibilidades, sin duda una de las más preciadas tanto por la doctrina jurídica como por los actores del comercio dadas las ventajas procesales que lo distinguían de la justicia ordinaria ${ }^{3}$.

La generalidad de la doctrina jurídico-mercantil de la Europa moderna apostó por formas como el arbitraje para solventar las confrontaciones profesionales, y fue unánime en su rechazo al pleito entre mercaderes y a su recurso a los tribunales para remediar las situaciones conflictivas que suscitaba la práctica de la mercatura. Teóricos como los ingleses Gerard Malynes y Daniel Defoe, el francés Jacques Savary, el italiano Domenico Peri, o el castellano Tomás de Mercado, todos concebían al pleito como una afrenta directa contra los valores de amistad y las buenas maneras que debían regir la profesión mercantil ${ }^{4}$.

Ciertamente, aquel modelo teórico de reluctancia al pleito en la profesión mercantil, fue también el modelo de comportamiento deseado por los comerciantes de la Carrera de Indias. Los pleitos desarrollados en la Casa de la Contratación de Sevilla, institución real ocupada de la regulación del tráfico ultramarino que, entre muchas otras funciones, sirvió como tribunal para resolver los problemas civiles y criminales derivados de la Carrera de Indias 5 , evidencian cómo algunos mercaderes decidían apartarse de pleitos cuando

3 A pesar de la valía jurisdiccional del arbitraje para la actividad mercantil, la figura sigue siendo un tema historiográfico pendiente, especialmente en el caso hispánico e indiano, donde escasean los trabajos sobre la materia y los existentes se dedican a cuestiones legalistas, alejados de los matices propios de la práctica cotidiana. El tratamiento del arbitraje en Castilla y en la América colonial ha sido abordado por Merchan, 1981 y por Cruz Barney, 2000: 53-110, desde una perspectiva puramente normativista. El trabajo de Antonio Miguel Bernal es la única excepción que trata el tema del arbitraje en el contexto del comercio atlántico. Bernal, 2008: 513-539. Siempre desde una óptica legalista, pero en el ámbito aragonés, sobresalen los estudios de Royo Pérez, 2016: 141-195. Valiño Arcos, 2002. El arbitraje, $\mathrm{y}$ en general por los medios alternativos al litigio para resolver conflictos mercantiles, ha suscitado mayor interés en Europa durante los últimos años. Garnot, 1996. Dyson, 2013. Maccioni, 2016.

4 Petit, 1997: 63; 2008: 25-26.

5 Creada en 1503 por orden real, la Casa de la Contratación de Sevilla fue la institución ocupada de gestionar y administrar las comunicaciones e intercambios comerciales con el Nuevo Mundo. La Casa sirvió, entre otras cosas, de almacén, aduana y contaduría para las mercancías que circulaban entre la península y las colonias americanas, disponiendo asimismo de facultades jurisdiccionales sobre las causas civiles y criminales derivadas del comercio y la navegación indiana. A partir del año 1583 existió una audiencia propiamente dicha para la Casa, un tribunal expresamente destinado a resolver los problemas de relevancia jurídica resultantes de la Carrera de Indias. Schäfer, 2003: 30. Petit, 2003: 124-125. Cervera, 1997: 138. 
consideraban que la pretensión del demandante era justa. Así, cuando el capitán Agustín de Landecho echó a fondo su nao deliberadamente para evitar que la armada inglesa pudiera entrar y rapiñar el puerto de San Juan de Ulúa en 1595, algunos de los mercaderes a quienes el capitán había demandado en la Casa para que le reintegrara los 20.000 ducados que valía el navío «dixeron que hera mucha rrazon que se le pagase sin pleito alguno» porque de eso dependió que se salvara la plata del rey y la de los particulares ${ }^{6}$.

Sin embargo, evitar conflictos en el comercio de larga distancia fue una empresa difícil de conseguir. La generosidad mostrada por los cargadores de la nao del capitán Landecho resulta casi anecdótica frente al resto de la documentación judicial que evidencia que prescindir de soluciones jurisdiccionales, amigables o no, fue arduo en la Carrera de Indias. La estacionalidad del crédito, agudizada por la gravedad del contexto de la navegación y del comercio atlántico durante el siglo $\mathrm{XVI}^{7}$, empujó a los mercaderes afincados en Sevilla a pelear por sus intereses, prescindiendo en muchos casos de mecanismos de solución de controversias considerados «amigables» como el arbitraje. Pero los mercaderes pleiteaban no porque fueran afectos al litigio, sino porque de ello dependía su propia estabilidad financiera. El pleito, aunque enfadoso y costoso, fue un recurso necesario que formó parte de la cultura mercantil de la época moderna, y saber litigar era un asunto tan crucial en la formación del mercader como los conocimientos de aritmética o contabilidad ${ }^{8}$.

De hecho, conocer el derecho y la práctica de los tribunales locales fue un asunto esencial para el desarrollo del comercio de larga distancia, donde la fragmentación jurisdiccional y la diversidad de usos y prácticas comerciales imposibilitaron la formación de un ius mercatorum universal ${ }^{9}$, obligando a los mercaderes a involucrarse en los usos y procedimientos jurídicos de las localidades que interesaban a sus tratos para, en un momento dado, protegerlos a

${ }^{6}$ Notificación de la demanda interpuesta por el capitán Agustín de Landecho a los mercaderes interesados en los bienes que transportaba la nao Santa María de Begoña, 4 de marzo de 1596, Archivo General de Indias, Sevilla (AGI), Contratación, legajo 741, exp. 6, f. $7 \mathrm{r}$.

7 El éxito de la navegación y del comercio transatlántico estuvo condicionado por varios factores: primero, el clima y la piratería, ambas causas de numerosos accidentes marítimos registrados en la Carrera de Indias. Luego, la voracidad de la hacienda real, manifiesta en las incautaciones de las remesas privadas de metales preciosos procedentes del Nuevo Mundo. Pérez-Mallaína, 1996: 197. Aznar, 2010: 63-89. Lorenzo Sanz, 1977: 280-282. Sardone, 2012: 21-64.

8 Petit, 1997: 15-70. Caunedo, 2012: 37-51. Jeannin, 1995: 385-387.

9 Cordes, 2005: 53-67. Baker, 1979: 298-322. Donahue, 2005: 69-120. Volckart y Mangels, 1999: 427-450. Frankot, 2007: 151-172. Kadens, 2004: 46-47. 
través de las plurales alternativas jurisdiccionales. No obstante, y a pesar de las dificultades, las fuentes evidencian la disposición de muchos comerciantes de agotar otras instancias jurisdiccionales alternativas al litigio.

\section{LAS VENTAJAS JURISDICCIONALES DEL ARBITRAJE}

Precisamente el arbitraje se presentaba como la alternativa más adecuada para resolver conflictos mercantiles gracias a su brevedad y bajo costo, así como por servir como un instrumento pacificador de las partes confrontadas, restaurando, en mayor o menor medida, los vínculos que en la esfera privada unían a los interesados ${ }^{10}$. Por medio del arbitraje, una o varias terceras personas reconocidas por las partes en disputa aceptaban la comisión de zanjar sus diferencias al margen de los tribunales ${ }^{11}$. En Castilla y en Indias la decisión de los árbitros era jurídicamente vinculante para las partes, no obstante carecer de poderes jurisdiccionales formales; esto es, a pesar de que los árbitros no eran jueces profesionales ni formaban parte de un tribunal públicamente establecido ${ }^{12}$. Los árbitros actuaban como jueces y en tal calidad creaban derecho, determinando la solución del caso conforme a lo que ellos consideraban justo ${ }^{13}$. En esta línea, un simple concierto o acuerdo entre las partes para desistirse del pleito o para aceptar nuevas condiciones contractuales que pusieran fin a sus diferencias, no comportaba un arbitraje. Para que éste tuviera lugar era indispensable la presencia de un tercero que, actuando como juez, dirimiera la controversia conforme a su arbitrio.

El arbitraje era el procedimiento de solución de controversias preferido en los consulados hispánicos e indianos, instituciones especializadas en la administración de justicia mercantil, que lo empleaban para avenir a los contrin-

10 Kuehn, 1991: 19-74. White, 1978: 281-308. Miller, 1984: 95-134.

11 Wolaver, 1934: 132-146.

12 Conviene estar sumamente atentos a la textualidad de las fuentes por existir diferencias esenciales entre los términos árbitro y arbitrador. El primero, el árbitro, actúa con potestad jurisdiccional y su sentencia tiene carácter vinculante sin que ésta pueda ser reestudiada en otra corte. Por su parte, el arbitrador es un individuo escogido por los adversarios para avenirlos sin que su decisión resulte jurídicamente vinculante quedando su juicio reducido al albedrío de buen varón. Merchan, 1981: 70-77. Martone, 1984: 3-21.

13 D’Ors, 1953: 16-17. Si bien el prior y los cónsules del Consulado de Sevilla eran mercaderes y no juristas, su actividad jurisprudencial les mereció la calidad de jueces, condición reconocida tanto por la comunidad como por la legislación. Las ordenanzas del Consulado se refieren a ellos como jueces de su majestad, atribuyéndoles los mismos honores y reverencias que a los juristas letrados. Véase la ordenanza número 20 del conjunto legislativo de 1556. Heredia, 1973: 164. 
cantes antes de iniciar un proceso judicial. En el caso del Consulado de Sevilla $^{14}$, los cónsules debían intentar conciliar a los litigantes y conminarlos a desestimar un pleito inclinándose por la vía arbitral. Los propios cónsules podían actuar como árbitros o bien delegar esa función en otros mercaderes, siempre que por su capacidad y conocimiento del asunto pudieran conseguir una mejor administración de justicia para los pleiteantes ${ }^{15}$. Si la conciliación era infructuosa, entonces daba inicio un litigio formal en el Consulado cuya sentencia ejecutaban los alguaciles de la Casa de la Contratación ${ }^{16}$.

El arbitraje podía tener una finalidad preventiva, evitando iniciar pleitos en los tribunales formales, y también resolutiva, suspendiendo un proceso judicial iniciado en algún tribunal para delegar la solución del conflicto a los árbitros reconocidos por los litigantes. Es evidente que la rentabilidad del arbitraje se verificaba en una solución de justicia mucho más ágil y económica que aquella ofrecida por la jurisdicción ordinaria, suponiendo el ahorro de los costos procesales a los litigantes. Pero el arbitraje aportaba otro beneficio igualmente importante para la práctica comercial: significaba un valioso indicador de la reputación de los mercaderes pleiteantes. Decidir avenirse fuera de la corte o desistirse de un proceso denotaba un ánimo de paz y concordia en los negocios muy apreciado no sólo por la parte contraria, pues manifestaba la intención de conservar la amistad entre los contrincantes ${ }^{17}$, sino también por el gremio de mercaderes y, sobre todo, por potenciales socios comerciales de los litigantes.

${ }^{14}$ En 1543 el entonces príncipe Felipe autorizó la creación en Sevilla de un Consulado de mercaderes para que a través de un prior y unos cónsules pudieran conocer y determinar los pleitos entre comerciantes sobre materias de comercio. Debían juzgar según y como lo hacían el prior y cónsules de la ciudad de Burgos, sin dar lugar a pleitos ni dilaciones, sino conforme al uso y estilo de los mercaderes. La creación del Consulado significó la sustracción formal de la jurisdicción mercantil a la Casa de la Contratación que desde su fundación se ocupó de dichos asuntos, para quedar ahora exclusivamente en manos del prior y de los cónsules. Trueba, 1998: 40-41. Laviana, 2006: 25-26. Ruiz Rivera y García Bernal, 1992: 51-80. Vas, 2004: 93-94. Martiré, 1997: 229-235.

15 Coronas, 1994: 251-279; 1979: 61-63.

16 Ordenanzas número 6 y 13 de 1556. Heredia, 1973: 156-158. Real, 1968: 281-291.

17 El imperio de la concordia, así como la conservación de la amistad que tenían desde años atrás, fue lo que movió a los mercaderes Vasco Rodríguez, dueño y capitán de la nao Nuestra Señora del Hospital, y Francisco Correa, maestre de la misma, a desistirse de un pleito por las cuentas del maestraje del navío e iniciar un arbitraje: «E agora por uia de paz y concordia, y por nos quitar y apartar del dicho pleyto y conseruar nuestra amistad e por otras justas caussas que a ello nos an mobido, nos auemos convenydo e conçertado entre nosotros de comun acuerdo e conformidad en tal manera que nos desistimos y apartamos del dicho pleyto e causa, e lo damos por ninguno e de ningun efeto e valor», Escritura de desistimiento del pleito de los mercaderes Vasco Rodríguez y Francisco Correa, presentada el 11 de abril de 1584, AGI, Contratación, legajo 724, exp. 9, s/f. Vallejo, 1994: 211-270. 
El interés en evitar pleitos y tribunales favorecía la construcción de una imagen pública prestigiosa, condición indispensable para ejercer el comercio $^{18}$. En ciertos supuestos el arbitraje fue un privilegio a través del cual los acreedores premiaban la honestidad y buena fe de sus deudores; un premio que podía incluso lesionar los intereses económicos de los acreedores. Esa es la situación que se observa en el compromiso arbitral que en 1585 firmaron Bartolomé de Grimaldo y sus socios. En él los acreedores renunciaban al cobro de todas las deudas de plazo vencido, se desistían de cualquier pleito iniciado por esa causa y eximían al deudor de toda pena, patrimonial o privativa de la libertad, que por ley pudieran reclamar en su contra. Lo anterior en virtud de la disponibilidad de Grimaldo para que sus acreedores revisaran libremente su contabilidad, recompensando su honestidad por no haberse alzado con sus bienes ni huido de la ciudad ${ }^{19}$.

Los beneficios del arbitraje se manifestaron también en la calidad de los jueces árbitros. Sin excepción, los árbitros fueron expertos en materias mercantiles, ya fuera porque ellos mismos ejercían el comercio o porque entendían en cuestiones técnicas de la profesión ${ }^{20}$. En las fuentes revisadas los árbitros eran mayoritariamente hombres dedicados al comercio y a la navegación, como cónsules ${ }^{21}$, maestres o capitanes de navíos habituados al manejo de la contabilidad en la navegación ${ }^{22}$, y hasta expertos en matemáticas y

18 Lamikiz, 2010: 141-144.

19 «Y todo lo que en virtud se hiciere (del arbitraje), valga e sea firme ahora y en todo tiempo, por cuanto confesamos y declaramos que en la persona de Bartolomé de Grimaldo no hubo falta ni defecto alguno, porque no alzó libros ni bienes ningunos, y todo nos los dejó en nuestras manos. Y damos por ningunas cualquier escrituras y cédulas o mandamientos y recaudos que contra él tengamos, no embargante que los plazos estén ya cumplidos o por cumplir, porque de ello no habremos de usar sino fuere a los plazos contenidos en la sentencia y declaraciones de los dichos jueces árbitros y no en más», Concierto de Bartolomé de Grimaldo con sus acreedores, 29 de noviembre de 1585, Archivo de Protocolos, Sevilla, (APS), Real Audiencia, legajo 29193, f. 21v.

${ }^{20}$ Bernal, 2008: 517.

21 Pedro Díaz de Abrego, prior del Consulado en 1594, 1601 y 1602, fue nombrado como tercer árbitro en discordia por los mercaderes Leonardo de Ayala y Diego Pérez de Porras, según consta en el poder otorgado a los árbitros ante el escribano Juan de Tordesillas el 14 de enero de 1596. Autos de Leonardo de Ayala con Diego Pérez de Porras, sobre la cuenta de los gastos de la nao la Concepción, de la cual eran dueños por mitad, año 1593, AGI, Contratación, legajo 736 B, exp. 23, s/f.

${ }^{22}$ Véase el arbitraje al que se someten de un parte, Pedro de Araneder, dueño y maestre de la nao Santa Ana y, de la otra, los mercaderes interesados en los bienes que llevaba su nao y que se dañaron o perdieron a su regreso a España desde la Habana. El maestre nombró como su árbitro a otro maestre, Gaspar de Maya, mientras que los comerciantes nombraron a uno de los suyos, Domingo de Corcuera, como consta en el poder conferido a los árbitros el 8 de junio 
contabilidad $^{23}$. Su pericia los hacía merecedores del reconocimiento y de la confianza de los mercaderes, quienes consideraban sus valoraciones como óptimas para la solución del conflicto y, luego en tanto, mejores y más eficientes que otras alternativas legales.

Los mercaderes también depositaron esa confianza en los profesionales del derecho. Es notable la intervención como árbitros de algunos de los abogados más activos en la Real Audiencia de Sevilla, la Casa de la Contratación y el Consulado. Distinguidos letrados como el doctor Francisco Juárez de Castilla Galindo, el licenciado Enbrun de Lancia ${ }^{24}$, o el licenciado Lucas de Antezana, se citan con frecuencia en los acuerdos arbitrales que se custodian en el archivo notarial de Sevilla. Su presencia manifiesta la confianza de la comunidad mercantil en los letrados de Sevilla, una confianza fundada en la autoridad que les otorgaba su conocimiento teórico del derecho y su experiencia en el foro.

En lo que concierne al desarrollo del procedimiento, en Castilla y en Indias el arbitraje se formalizaba con una escritura de compromiso elaborada ante un fedatario público ${ }^{25}$. El contenido del documento es casi siempre el mismo, permitiendo identificar una serie de elementos comunes a todos los conciertos arbitrales. La escritura contenía el poder conferido por los declarantes a cierta persona o personas - los árbitros - por virtud del cual les eran reconocidas facultades jurisdiccionales especiales para dirimir la controversia especificada en el documento. Las partes podían acordar que una única persona decidiera la justicia de su caso, o bien, que cada una nombrara a su propio árbitro, a modo de asegurar la defensa de sus pretensiones durante el debate. Para ello se preveía la existencia de un tercer árbitro en discordia, el cual podía ser nombrado en consenso por los interesados o por los árbitros (si estaban habilitados para ello), para que resolviera en caso de desacuerdo entre los primeros ${ }^{26}$.

de 1595 ante el escribano Juan de Velasco. Autos de Pedro de Araneder, maestre, con los interesados en su nao sobre avería gruesa, año 1595, AGI, Contratación, legajo 740, exp. 9, s/f.

${ }^{23}$ Principalmente Julio Ferrofino, especialista en matemáticas al servicio de la Casa de la Contratación, quien aparece en casi todos los procesos que involucran contabilidad como los repartimientos por avería gruesa y las cuentas de navíos.

${ }^{24}$ La constante aparición del licenciado Juan Enbrun de Lancia en los pleitos no es gratuita. Además de su activa intervención como abogado en los distintos tribunales de Sevilla, también detentó diversos cargos judiciales que aluden a su gran prestigio profesional. En 1599 aparece como Teniente del Asistente de Sevilla. Años más tarde, en 1632, sería nombrado como abogado de los pobres de la ciudad de Sevilla, en lugar del licenciado Agostino Casquier. AMS, Sección II, 10/174, ref. H/664. Asimismo, en 1638 se le verá actuando como abogado del fisco de la Inquisición. AMS, Sección II, 15/172, ref. H/669. Alonso y Garriga, 2013: 42-45.

25 Merchan, 1981: 207-213. Cruz Barney, 2000: 60-61.

26 El acuerdo arbitral entre Pedro de Veiztegui, maestre de la nao San Buenaventura, y los interesados en las mercancías que iban en ella y que se dañaron en el viaje desde Santo 
El compromiso arbitral asumido por los mercaderes confrontados implicaba obligaciones comunes muy concretas. La primera y más esencial de todas, someterse a la potestad jurisdiccional del juez árbitro. Dicha potestad era plenamente reconocida por las partes, quienes se comprometían a obedecerlo llanamente y sin ninguna contradicción, invalidando expresamente cualquier tipo de acción judicial tendiente a revocar o a invalidar el laudo, utilizando fórmulas como esta: «e si contra ello fueremos o vinieremos, o la contradijeramos o reclamaremos, queremos no ser oidos sobre ello y ser desechados de juiçio como cosa intentada por no parte» ${ }^{27}$. Tal obediencia comportaba una constricción patrimonial y moral para los involucrados. Por una parte, toda apelación o recurso a otras justicias era penalizada pecuniariamente con una suma ya establecida en el compromiso arbitral. Por otra parte, los interesados ofrecían su propia conciencia como garantía, jurando la observancia del laudo y prometiendo no acudir ante ninguna autoridad eclesiástica facultada para absolver el juramento y liberar su alma de cualquier condena moral ${ }^{28}$.

La duración del debate entre los conciliadores estaba igualmente programada. Los árbitros disponían de un periodo de tiempo razonable establecido por las partes, acorde a las dificultades del negocio a dirimir, para presentar su decisión a los involucrados en la disputa. La regla evitaba dilaciones innecesarias que desvirtuaran la brevedad del procedimiento, aunque si la complejidad del asunto lo ameritaba, el plazo podía ampliarse.

Para rematar las garantías, en los compromisos arbitrales las partes reforzaban la firmeza del laudo acogiéndose genéricamente a la potestad de las justicias de Sevilla o de otras partes para que los compelieran a cumplir la sentencia de los árbitros. Mayoritariamente se facultaba a las justicias hispá-

Domingo hasta la Habana, lo ilustra perfectamente: «por quitarnos de pleytos y gastos somos conuenidos con vos el dicho maestre que Diego Pérez de Porras y Julio Ferrofino uean las pretençiones de vos el dicho maestre y las pretensiones que nos los dichos interesados podemos tener y pretender. Y que ambos a dos las determinen en todo el mes de otubre del presente año y agan repartimiento como les pareçiere, que por esta nos obligamos de pasar por ello y pagar la cantidad que nos fuera repartido». Veiztegui adjuntó dicho acuerdo a la demanda que puso en la Casa de la Contratación el 26 de octubre de 1596. Autos de Pedro de Veiztegui, maestre de nao, con los interesados en las mercancías de ella por avería gruesa, año 1596, AGI, Contratación, legajo 742, exp. 22, s/f.

27 Concierto de Bartolomé de Grimaldo con sus acreedores, 29 de noviembre de 1585, APS, Real Audiencia, legajo 29193, f. 21.

28 En el compromiso arbitral hecho entre Pedro de Araneder y los interesados en la carga de su nao, además de jurar el cumplimiento del laudo, las partes se obligaron a pagar 300.000 maravedíes más los gastos y costas que resultaran del proceso que iniciaran en contradicción de la decisión de los árbitros. Autos de Pedro de Araneder, maestre, con los interesados en su nao sobre avería gruesa, 8 de julio de 1595, AGI, Contratación, legajo 740, exp. 9, s/f. 
nicas e indianas para tales efectos, aunque la fórmula preferida por los pleiteantes dejaba abierta esta posibilidad a todas las jurisdicciones, fueran castellanas o foráneas. Creemos que la finalidad de esta amplitud de jurisdicciones en las cuales reclamar era evitar controversias legalistas en torno a la competencia de los tribunales para conocer y resolver el asunto. Con ello el posible deudor garantizaba contractualmente al acreedor que la sentencia de los tribunales se ejecutaría sin mayores complicaciones.

De hecho, el poder conferido por las partes para que cualquier tribunal sentenciara su causa preveía la más drástica de sus formas de coacción, la ejecución: «les damos el dicho poder para que nos liguen y obliguen asi por bia executiva como por aquella uia e forma que les paresçiere» ${ }^{29}$. Por medio de la vía ejecutiva el actor, con la simple presentación del laudo arbitral ante los jueces del tribunal, aseguraba su cumplimiento por medio del embargo de los bienes y hacienda del deudor y/o de sus fiadores, los cuales eran posteriormente rematados para pagar el crédito pendiente. El juicio ejecutivo era un procedimiento sumario, de modo que la ejecución era casi inmediata gracias a la omisión de las formalidades procesales, a la limitación de los plazos de prueba y de las alegaciones de las partes ${ }^{30}$.

Con tales concesiones las partes reconocían expresamente que el arbitraje tenía una importante limitación pues los árbitros carecían de poderes coercitivos que les permitieran obligar a los litigantes a cumplir el laudo, razón por la cual dependían de la potestad de los tribunales. En este sentido, e independientemente de arreglarse fuera de la corte, los pleiteantes continuaban supeditados a un juez con potestad públicamente reconocida, lo que les suponía una inversión inexcusable de tiempo y de dinero. Y no es que los árbitros no gozaran de la misma potestad pública que los jueces; la tenían, pero no disponían de los medios materiales indispensables para hacer cumplir sus decisiones, de ahí el recurso inexcusable a una corte formal.

\section{LOS LÍMITES DE LA JURISDICCIÓN ARBITRAL}

La carencia de facultades de los árbitros debilitó la eficacia del procedimiento arbitral. La necesidad de recurrir a la jurisdicción ordinaria creaba un

${ }_{29}$ Compromiso arbitral del 14 de enero de 1596 realizado ante el escribano Juan de Tordesillas. Autos de Leonardo de Ayala con Diego Pérez de Porras, sobre la cuenta de los gastos de la nao la Concepción, de la cual eran dueños por mitad, año 1593, AGI, Contratación, legajo 736 B, exp. 23, s/f.

30 Lumbreras, 1960: 250-251. Estepa, 1977: 98-99. Fairén, 2006: 516-517. Montero, 1994: 90. 
espacio nuevo de alegación que fue aprovechado por algunos litigantes, pues la justicia ordinaria ponía a su disposición una serie de recursos procesales que no dudaban en usar si les redituaba en algún beneficio. Negar el poder jurídicamente vinculante de la decisión de los árbitros, oponerse a la ejecución gestionada por el actor en los juicios ejecutivos, o alargar el proceso con pruebas y alegatos, son sólo algunas formas de sortear el cumplimiento del laudo.

Otras veces la justicia ordinaria no era simplemente un instrumento coercitivo al servicio de los árbitros. Existen casos donde se observa una duplicidad jurisdiccional de buena fe, en la cual los litigantes acuerdan mantener concomitantemente un litigio en la jurisdicción ordinaria y un arbitraje. La continuación del primero dependerá del éxito del segundo; esto es, si el laudo arbitral no satisfacía a los litigantes, éste no extinguía los efectos de la causa seguida ante el tribunal, sino que los dejaba pendientes, permitiendo con ello a las partes retomar el proceso en el estado en el que lo dejaron sin necesidad de empezar uno nuevo. Al contrario, si la sentencia de los árbitros era aceptada por los interesados, ésta extinguía los efectos de cualquier procedimiento incompleto en otras instancias jurisdiccionales ${ }^{31}$. En este supuesto el arbitraje ya no tenía una finalidad resolutiva, pues estaba condicionado a la aprobación del laudo por las partes, conllevando, al mismo tiempo, el riesgo de que alguno de los pleiteantes llevara la causa a otra jurisdicción.

El arbitraje, pese a sus incuestionables ventajas, tuvo asimismo defectos que, en un escenario judicial como el de Sevilla, lo posicionaron como una alternativa jurisdiccional más a disposición de los litigantes; una buena opción, pero no necesariamente la mejor. Como el resto de las justicias de la ciudad, el arbitraje poseía virtudes y defectos que los pleiteantes valoraban e instrumentalizaban de acuerdo a sus específicas necesidades e intenciones. Y es que avenir por arbitraje a los pleiteantes no era una tarea sencilla. Múltiples causas dificultaban el éxito del arbitraje, unas dependientes completamente de la voluntad de los litigantes y otras, por el contrario, ajenas a sus intenciones. Los problemas podían aparecer ya desde la elección de los árbitros, pues se requería el acuerdo conjunto de las partes. El escenario más conflictivo se

31 «Si los dichos comisarios no se conformaren en el dicho termino, que pasado nos an de quedar y quedan nuestros derechos a salbo y los pleytos y rrecaudos y escrituras en su fuerça y uigor e sin los ynouar ni alterar en cossa ninguna para que cada uno pueda seguir y pedir su justiçia como uiere que le conuiene. Y solo entiende que por el dicho termino suspendemos la prosecuçion dellos, y que se an de quedar y quedan en el punto y estado en que estan sin que los podamos seguir ni proseguir», Compromiso arbitral del 14 de enero de 1596 realizado ante el escribano Juan de Tordesillas, Autos de Leonardo de Ayala con Diego Pérez de Porras, sobre la cuenta de los gastos de la nao la Concepción, de la cual eran dueños por mitad, año 1593, AGI, Contratación, legajo 736 B, exp. 23, s/f. 
daba cuando cada uno de los interesados debía proponer a su árbitro. Si bien se buscaba que los árbitros fueran imparciales y que mantuvieran su parecer sobre los interesados al margen del conflicto, conseguirlo era difícil. El árbitro que cada parte nombraba fungía no sólo como juez sino también como un garante de sus pretensiones, de modo que el nombramiento de los árbitros podía comportar una transgresión a su neutralidad como jueces, pues los interesados solían elegir a personas con quienes tenían una relación de confianza anterior al conflicto.

La amistad entre el oponente y el árbitro, o los muchos tratos entre ellos eran hechos que, como es natural, los litigantes consideraban perjudiciales a sus intereses dada la presumible enemistad que el árbitro tendría para con ellos. En la mayoría de los casos, cualquier característica de los jueces que fuera valorada por alguna de las partes como potencialmente dañina para la imparcialidad del proceso, motivaba su recusación. Desde luego, la estimación de los pleiteantes sobre los árbitros era profundamente subjetiva y cualquier gesto del árbitro podía detonar la desconfianza de los litigantes. Ello daba lugar a malos entendidos que a su vez podían desencadenar otro proceso de conciliación, esta vez con el propósito de acordar el nombramiento de los árbitros.

Este problema fue bien entendido por Pedro Antonio Acharte y Hernando Barbosa, el primero dueño de la cuarta parte del filibote el Cazador y el segundo su maestre. Ambos decidieron someterse a un arbitraje a finales de 1591 para ajustar las cuentas del maestraje del navío. Para ello Barbosa nombró como su árbitro a Hernán Rodríguez Pereira, mientras que Acharte eligió a Juan Antonio. Los malestares empezaron cuando Barbosa solicitó la recusación de Juan Antonio, señalando que tenía interés en el negocio por ser dueño de una parte de la embarcación. Por su parte Acharte, destacando la malicia con la cual su opositor solicitaba a los jueces de la Casa de la Contratación la inhabilitación de su juez, no dudó en cobrarse con la misma moneda: «Hernando Barbosa lo recusa de maliçia (a Juan Antonio) porque el susodicho tiene notiçia destas quentas e porque no se acaben. Y porque yo tengo por odioso a Hernán Rodríguez Pereira, terçero nonbrado por la otra parte, porque trato con el çierto pleito en la real audiençia desta cassa, yo le recuso"32.

Otras veces el problema aparecía no por la desaprobación que los litigantes hacían de los árbitros, sino por la negativa de éstos de aceptar el cargo. La falta de tiempo y de disponibilidad de los candidatos podía complicar el desarrollo del arbitraje. En la mayoría de los casos el proceso arbitral impli-

32 Escrito de Pedro Antonio Acharte presentado ante la Audiencia de la Contratación, 6 de diciembre de 1591, AGI, Contratación, legajo 732, exp. 21, f. 10. 
caba una exigente inversión de tiempo y de esfuerzo. Había que revisar documentos, hacer cuentas y reunir evidencias para poder resolver con justicia, poniendo en riesgo de descuido los propios compromisos del juez árbitro. La negativa de los árbitros para asumir el cargo se observa en distintos pleitos, apremiando a las partes para encontrar nuevos candidatos que además fueran admitidos por el contrario. El citado Hernando Barbosa tuvo a su vez un pleito en 1589 con Juan Antonio como dueño de una parte del filibote el Cazador (también por las cuentas del navío). Inicialmente había nombrado por su juez y contador al licenciado Lucas de Antezana. Al poco tiempo Barbosa se vio obligado a nombrar a otro juez, Julio Ferrofino, alegando que Antezana era un hombre muy ocupado y sin tiempo para hacer las cuentas ${ }^{33}$.

Muchas fueron las contrariedades que debían superar quienes intentaban avenirse por la vía arbitral, a veces tan arduas que provocaban el fracaso de la conciliación extrajudicial. Si ya resultaba complejo avenir a dos personas, más difícil era arreglar a varios comerciantes enfrentados. En los concursos de acreedores o en los pleitos por avería gruesa donde convergían múltiples interesados, difícilmente el arbitraje tenía éxito. Ofrecer a todos los pleiteantes un laudo de su agrado era una empresa titánica, pues no faltaba el mercader inconforme que lo apelaba o que se inclinaba por otra vía jurisdiccional menos perniciosa para sus intereses. Con esto no se quiere insinuar que el arbitraje no operara en este tipo de circunstancias; lo hizo, pero individualmente, observándose avenencias, por ejemplo, entre el deudor y un determinado acreedor ${ }^{34}$.

La complejidad de la materia fue asimismo una condición a la que quedó supeditada la viabilidad del arbitraje. En los asuntos sobre cuentas de compañías o de maestraje, donde había que atender a todos los detalles sobre los ingresos y gastos erogados a cuenta de una compañía en amplios periodos de tiempo, cometer errores era fácil. El laudo arbitral podía ser desestimado por una o todas las partes si éstas se consideraban agraviadas por su injusticia al omitir o añadir algún cargo o abono que les afectara negativamente, motivando la acción judicial de los pleiteantes en otros tribunales.

33 Nombramiento realizado en septiembre de 1589. Autos de Juan Antonio y Francisca de Tovar, en su nombre, vecinos de Sevilla y dueños de la urca el Cazador, con Fernando Barbosa, maestre, sobre las cuentas de dicha urca, año 1589, AGI, Contratación, legajo 730 A, exp. 7, s/f.

${ }^{34}$ Así lo hicieron Francisco Juan Vila y su acreedor Antonio González, no obstante la existencia de otros acreedores. Las partes pactaron un arbitraje ante el escribano de Santo Domingo, Lorenzo García de Valdés, el 3 de julio de 1589. Autos de los acreedores a los bienes de Francisco Juan Vila, vecino de Sevilla, dueño de la nao Nuestra Señora de la Gracia, año 1589, AGI, Contratación, legajo 730 B, exp. 11, s/f. 
Los mercaderes Leonardo de Ayala y Diego Pérez de Porras reconocieron en un compromiso arbitral de 1596 el haber intentado avenirse previamente respecto de las cuentas de la compañía que tenían sobre la nao la Concepción, primero sin el auxilio de ningún tercero; luego acudieron al doctor Francisco Juárez de Castilla como árbitro, quien tampoco consiguió reconciliar a los pleiteantes: «el dicho dotor juarez castilla dio cierto paresçer contra el qual tenemos dicho de agrabios y sobre lo demas no nos auemos podido conformar agora por bien de paz e concordia» ${ }^{35}$. El fallo del arbitraje motivó el seguimiento de la causa en la Casa de la Contratación, proceso que más tarde fue suspendido en atención a un segundo arbitraje. Esta vez serían el doctor Juárez de Castilla y el licenciado Juan Enbrun de Lancia quienes resolverían la causa.

Indudablemente, tantos arreglos fallidos enfadaron a los involucrados, quienes por zanjar definitivamente la controversia intentaron por distintas vías conseguir una sentencia firme y, por supuesto, beneficiosa. Llama la atención los numerosos pleitos que ambas partes se pusieron en diferentes tribunales; prácticamente agotaron todas las instancias de la ciudad de Sevilla ${ }^{36}$. Ciertamente, por encima de un intento real de solución pareciera existir cierto ánimo malicioso y manipulador, no sólo revelado por los pleitos que pendían en diferentes jurisdicciones, sino por la agresión dolosa contra la eficacia de cualquier acuerdo. En 1600 Leonardo de Ayala volvía a presentarse ante los jueces de la Casa incomodado por el laudo que cuatro años antes habían emitido los árbitros. Solicitaba la reducción de la sentencia arbitral al simple albedrío de buen varón ${ }^{37}$. Diego Pérez de Porras no tardó en recordar a su contrincante la calidad de cosa juzgada del pleito y la firmeza de la sentencia arbitral, misma que más tarde fue hecha cumplir por los oidores de la Casa.

En la práctica el arbitraje era un procedimiento a veces incierto. El hecho de que la conciliación no siempre rindiera frutos podía prolongar los pleitos

35 Compromiso arbitral del 14 de enero de 1596 realizado ante el escribano Juan de Tordesillas. Autos de Leonardo de Ayala con Diego Pérez de Porras, sobre la cuenta de los gastos de la nao la Concepción, de la cual eran dueños por mitad, año 1593, AGI, Contratación, legajo $736 \mathrm{~B}$, exp. 23, s/f.

36 Leonardo de Ayala y Diego Pérez de Porras acordaron en el compromiso arbitral que firmaron en 1596 desistirse de todos los pleitos que tenían pendientes. Eso incluía, concretamente, cuatro pleitos iniciados en 1595 a petición de Ayala en la Casa de la Contratación. Véase AGI, Contratación, legajo 740, expedientes 22, 23, 24 y 25. Por su parte, Pérez de Porras se desistió de dos pleitos más, uno ante el alcalde Francisco de Herrera, y otro ante el alcalde Juan González de Solórzano.

37 Escrito aportado por Leonardo de Ayala a los autos de Leonardo de Ayala con Diego Pérez de Porras, sobre la cuenta de los gastos de la nao la Concepción, el 26 de octubre de 1600, AGI, Contratación, legajo 736 B, exp. 23, s/f. 
por años, igual que aquellos que se desarrollaban ante la justicia ordinaria. Como lo ilustra el pleito entre Ayala y Pérez de Porras, las controversias en torno a las cuentas de la nao la Concepción comenzaron en 1592 y todavía ocho años más tarde, después de dos arbitrajes, seguían enfrentados por esa causa. Evidentemente, la falta de acuerdo daba lugar a juicios en cualquiera de los tribunales de Sevilla, agudizando la propensión de los litigantes a manipular las distintas jurisdicciones de la ciudad maliciosamente, con el interés de presionar a la parte contraria más que finiquitar la disputa. Numerosos casos reflejan una abierta instrumentalización del arbitraje de parte de los interesados para suspender un proceso iniciado en alguna corte argumentando el intento de un acuerdo arbitral con la contraparte. La maniobra obedecía a un interés por ganar tiempo que podía utilizarse tanto para negociar como para presionar y desgastar al oponente.

El uso malicioso del arbitraje era un problema viejo. Desde 1549 las cortes solicitaron al emperador Carlos remediar el asunto para evitar los gastos y retrasos que suponía a las partes el iniciar y suspender pleitos so pretexto de arreglos arbitrales inútiles. La solución ofrecida por el monarca fue simple: los jueces que conocieran de un litigio en el cual ya mediara un laudo arbitral, tenían que hacerlo cumplir provisionalmente, debiendo el beneficiado por la sentencia dar una fianza suficiente ${ }^{38}$. Con ello se evitaba un nuevo pleito y se vigorizaba la decisión de los árbitros. La solución estuvo operativa al menos durante el siglo XVI, siendo los jueces de la Casa de la Contratación especialistas en su cumplimiento ${ }^{39}$.

Ante este escenario el arbitraje, como mecanismo jurisdiccional propio de la cultura de mercaderes, fue un instrumento que no siempre logró proteger los derechos de propiedad en juego en un pleito. De hecho, su eficacia estuvo

38 Fairén, 2006: 517-518.

39 Como se ve en el pleito que tuvo lugar en 1598 entre los mercaderes Gaspar de Maya y García de Remón Somedo. Este último acude a la Casa de la Contratación para que los jueces hagan cumplir la sentencia del arbitraje al que las partes se habían sometido previamente, así como para reclamar el pago de otras deudas. Todo indica que ambos comerciantes tuvieron una compañía en la nao nombrada «la Concepción» de cuyos fletes y cuentas surgieron diferencias. Por ello acordaron someterse a un arbitraje privado, nombrando a Pedro de la Helguera y a Cristóbal Romero, también mercaderes, como árbitros que definieran las cuentas de la nao. El laudo arbitral resolvía que Maya pagara 173.868 maravedís a Somedo, mismos que, a un año de la emisión de la sentencia (junio de 1597), no le habían sido pagados. A tan sólo 15 días de que Somedo presentara la demanda en la Casa de la Contratación ( 2 de junio de 1598), los jueces embargaron los bienes de Maya por el monto al que lo condenaron los jueces árbitros y, en poco más de dos meses, ya habían dictado sentencia de remate en su contra. Autos de García de Remón Somedo con Gaspar Moya sobre la cuenta de su nao, año 1598, AGI, Contratación, legajo 745, exp. 7, s/f. 
subordinada al auxilio de los tribunales. Esto no significa que el procedimiento no haya funcionado en ningún caso. Obviamente a la luz de los pleitos son más llamativos los defectos que los beneficios del procedimiento, pues cuando se alude a un arbitraje en un litigio es casi siempre porque éste ha fracasado. Seguramente muchos arbitrajes tuvieron buen término, aunque difícilmente podría estimarse su cifra dada la complejidad de su identificación. La única posibilidad sería rastrear en los archivos notariales los acuerdos arbitrales firmados por los pleiteantes, y aun así el solo acuerdo no revelaría el éxito del arbitraje, sino nada más una cifra aproximada sobre su práctica. En este trabajo hemos de conformarnos con las alusiones que a ellos se hacen en los pleitos, que en algunos casos adjuntan una copia del concierto arbitral y son los mismos interesados quienes detallan en sus peticiones la suerte del procedimiento.

\section{El respaldo de la Casa de la Contratación a la práctica DEL ARBITRAJE EN EL CONTEXTO DE LA CARRERA DE INDIAS}

Que los mercaderes involucrados en la Carrera de Indias acudieran de ordinario a los tribunales reales para resolver sus pleitos demuestra, por una parte, que el arbitraje no siempre fue el mecanismo elegido por los mercaderes para resolver disputas mercantiles. Por otra parte, la presencia de comerciantes en las cortes puede entenderse como una muestra de la confianza que en mayor o menor medida depositaban los mercaderes en las instituciones, sobre todo considerando la disponibilidad de otras instituciones especializadas en materias de comercio como los consulados. Dicha confianza puede tener su origen en la labor desempeñada por los tribunales en la resolución de los pleitos; concretamente en cómo resolvían los conflictos. Los tribunales funcionaron como espacios públicos para que las partes confrontadas legitimaran sus reclamos, desempeñando una labor de certificación de derechos y de obligaciones ${ }^{40}$; pero no necesariamente de un modo violento o desgastante para los interesados. Aún en el seno de las audiencias hubo espacio para la concordia. En ellas los jueces sirvieron como reconciliadores públicos de los litigantes en conflicto, de forma similar a la labor que debían ejercer tanto los cónsules como los árbitros ${ }^{41}$.

40 Ago, 1998: 157.

41 Algo parecido ocurría en los Países Bajos, donde las cortes centrales y provinciales podían resolver los pleitos simplemente a través de la amigable composición. Gelderblom, 2013: 126-133. 
La diferencia entre el proceder de los oidores y aquel de los árbitros, consistió esencialmente en que ellos arbitraban desde arriba; es decir, gestionaban el desarrollo del arbitraje a través de un litigio formalmente iniciado por los litigantes en su tribunal, pero delegando el conocimiento y la resolución de la sustancia del litigio a terceros especialistas — los árbitros - en la materia sobre la que versara la cuestión. Por ley, los magistrados de los tribunales castellanos tenían prohibido servir como árbitros en las causas que ante ellos se sustanciaran ${ }^{42}$. De esta manera, los jueces, sin resolver directamente el fondo del asunto, contenían a través de un proceso iniciado ante ellos por los pleiteantes las posibles inconformidades y evasivas de éstos con respecto a la decisión de los árbitros, garantizando potestativamente el cumplimiento del laudo.

En la Casa de la Contratación esta práctica es muy clara en la solución de pleitos relacionados con la contabilidad de compañías mercantiles. Las controversias sobre cuentas de compañías constituyeron el escenario adecuado para la práctica de un arbitraje especializado en su aclaración, un arbitraje que la doctrina jurídica mercantilista castellana ya contemplaba ${ }^{43}$, y ampliamente extendido tanto en el ámbito comercial mediterráneo como en el de la Carrera de Indias ${ }^{44}$. Las partes en disputa sometían la evaluación de las cuentas de una empresa común al escrutinio y valoración de uno o varios terceros contadores, buscando con ello aclarar cualquier error y definir claramente los saldos que alcanzaran a cada una de las partes de una forma pacífica.

El elemento distintivo de esta forma de conciliación radicó en su grado de especialización, pues los terceros contadores tenían que ser conocedores de materias contables para que su juicio fuera reconocido como valedero por las partes enfrentadas. Precisamente dicho reconocimiento era el que podía dificultar la eficacia del método, pues alguno de los interesados podía desaprobar las cuentas presentadas por los terceros contadores. Y es que la complejidad de los negocios aumentaba los riesgos de incurrir en el error, causa principal de la inconformidad de los interesados. Pero en ocasiones el análisis escrupuloso que los contadores pudieran hacer de las cuentas no bastaba para satisfacer a los pleiteantes, quienes podían objetar su decisión y recusarlos, buscando un resultado mucho más benigno en el juicio de un nuevo contador.

Los interesados podían acudir a alguno de los tribunales hispalenses bien para hacer cumplir las cuentas previamente realizadas y que una de las partes intentaba desestimar, o bien para que los magistrados se ocuparan directamente de la gestión del arbitraje, particularmente del nombramiento de los terce-

\footnotetext{
42 Merchan, 1981: 91-96.

43 Martínez Gijón, 1979: 155-173.

44 Bernal, 2008: 517.
} 
ros contadores y de obligar a las partes a asumir las responsabilidades patrimoniales que les resultaran de las cuentas presentadas por los árbitros. Todo indica que la Casa de la Contratación fue una corte especialmente atractiva para los pleiteantes que intentaban resolver asuntos sobre cuentas de compañías, pues la institución disponía de la estructura administrativa y material necesaria ${ }^{45}$. Los jueces de la Casa estaban investidos con potestad suficiente para obligar a las partes a efectivamente avenirse por la decisión de los terceros contadores nombrados por los propios pleiteantes. De hecho, con esa intención se presentaban en la audiencia, como hizo Hernando Home: «pido que mande a la otra parte que me de quenta de las naos y de sus prouechos y que para ello nombre a un terçero contador que haga las quentas que yo de mi parte nombro a Antonio de Corquera» ${ }^{46}$.

Los jueces de la Casa tenían asimismo facultad para sancionar la desidia de los pleiteantes que no se sentaban a hacer cuentas con sus socios o que se negaban a nombrar a su tercero contador a través de multas e incluso la cárcel. Penas pecuniarias también operaban para los contadores ya designados por los litigantes cuando se retrasaban en la elaboración de las cuentas. En este supuesto se encontraron en 1590 los mercaderes Cristóbal de Santana, Antonio de Villalpando y Pedro de la Cal, dueños por partes iguales de la urca llamada el Perro. Santana se presentó en la Audiencia de la Contratación para solicitar a los jueces que compelieran al resto de los interesados para que hicieran cuentas con él respecto de los gastos y beneficios del navío, y les mandaran nombrar un tercero contador que arbitrara por sus intereses en la elaboración de la cuenta. Por su parte nombraba como contador a Cristóbal Castellanos, mientras que Villalpando nombró al licenciado Diego de Andino y Pedro de la Cal llamó al mercader Juan de Escobar. De los autos se desprende la tardanza de los contadores en elaborar la cuenta, misma que fue denunciada por Santana a los jueces de la Casa, quienes apercibieron a los contadores para presentar sus resultados dentro de un plazo de 6 días so pena de 20 ducados de multa por cada día adicional de retraso ${ }^{47}$.

45 En el AGI se conservan 33 pleitos sobre la materia tan sólo entre los años 1583 y 1598 , todos contenidos en la sección Contratación, legajos 723-746.

46 Demanda presentada en la Audiencia de la Contratación por Hernando Home en contra de su hijo Domingo Yáñez Home, por virtud de la cual le solicita las cuentas de la nao llamada la Catalina y de otro navio de aviso que fue a la Nueva España, 22 de enero de 1598, AGI, Contratación, legajo 746, exp. 23. s/f.

47 Apercibimiento realizado en diciembre de 1590. Autos de Cristóbal de Santana Pareja, dueño de la tercera parte de la nao el Perro, castellanizada como San Lázaro, con Antonio de Villalpando y Pedro de la Cal, dueños de las otras dos partes, sobre la cuenta del navio, año 1590, AGI, Contratación, 731 B, exp. 28, s/f. 
Raramente el retraso en la entrega de la cuenta se debió a la negligencia de los contadores, coyuntura normalmente originada por una cantidad excesiva de trabajo que les impedía ocuparse del asunto. Un problema que las partes resolvían nombrando un nuevo contador con mayor disponibilidad ${ }^{48}$. La mayoría de las veces eran los propios litigantes quienes retrasaban el arreglo por medio de la ocultación de las pruebas y de los libros de contabilidad requeridos por los contadores para resolver ${ }^{49}$, aunque también la falta de acuerdo entre los contadores podía estancar el procedimiento. Retomando el ejemplo anterior, fue Juan de Escobar, contador nombrado por Pedro de la Cal, quien estuvo en desacuerdo con los resultados de la cuenta; un problema cuya solución, de nuevo, estuvo en manos de los jueces del tribunal. Ya que los litigantes iniciaban un proceso judicial ante los oidores de la Casa, podían solicitar el nombramiento de un contador de oficio cuando aquellos nombrados por las partes no conseguían acordarse. En este caso, los jueces sugirieron la intervención de Julio Ferrofino para dirimir la controversia.

La frecuencia con la cual los mercaderes se presentaban en la Casa de la Contratación para sustanciar conflictos contables no es casual. A diferencia de otros tribunales hispalenses, la Casa era además un centro científico, una cámara de conocimiento ${ }^{50}$ en la cual convergían especialistas de diversas materias (entre ellas matemáticas y contabilidad) para participar en las actividades docentes de la escuela náutica y de cosmografía que tenía allí su sede. Puede decirse que la Casa tenía a su disposición los servicios de una nómina de expertos, mereciendo por ese hecho la confianza de los pleiteantes. Julio Ferrofino formó parte de aquel elenco de especialistas, pues a finales del siglo enseñaba artillería naval en la Casa. Desde 1583 hasta 1595 será el protagonista indiscutible de los arbitrajes contables desarrollados en la Casa de la Contratación, al igual que de las valoraciones sobre los repartimientos de gastos por

48 Especialmente problemático fue el nombramiento de los terceros contadores en la cuenta que Cristóbal Coello y Baltasar de Valzola intentaban realizar sobre la nao el Rosario. Por las muchas ocupaciones de los contadores, ambas partes tuvieron que nombrar en varias ocasiones a nuevos contadores entre septiembre de 1595 y abril de 1596. Autos de Cristóbal Coello, maestre de la nao el Rosario y partícipe de ella con Gracián Valzola, por sí y como heredero de Antonio Carrillo, sobre la cuenta de la dicha nao, año 1595, AGI, Contratación, legajo 739, exp. 4.

49 Así lo denuncia a los jueces de la Casa Bartolomé de Arquero, quien el 25 de julio de 1592 señaló que la contraparte, Luis Marco Reinoso, se negaba a entregar los papeles al contador para hacer la cuenta. Pidió a los jueces que lo pusieran preso hasta que diera a Julio Ferrofino los libros de contabilidad. Autos de Luis Marco Reinoso con Bartolomé de Arquero y su hija María de Arquero, sobre la cuenta de la nao santa Ana de que eran dueños por mitad, año 1592, AGI, Contratación, legajo 734, exp. 4, s/f.

50 Barrera, 2006: 35-55. Cañizares-Esguerra, 2006: 19. 
avería gruesa. Numerosos arbitrajes por cuentas de compañías fueron resueltos por Ferrofino, ya fuera como tercero contador nombrado de oficio, o siendo directamente elegido por alguna de las partes. Julio Ferrofino contaba con una sólida trayectoria al servicio de Felipe II. Era un jurista y matemático de origen milanés que en su juventud sirvió como abogado del monarca castellano en la corte romana. A partir de 1595 ocupó la cátedra de matemáticas en la Academia de Matemáticas de Madrid hasta su muerte en 160451.

La mayoría de los contadores seleccionados por los litigantes eran también mercaderes, aunque hubo quien se inclinó por acudir directamente a especialistas de la talla de Ferrofino o, como ya hemos señalado, a los abogados que litigaban en los diferentes tribunales hispalenses ${ }^{52}$. La tendencia en la selección es bastante lógica. La intención de las partes era depositar sus pleitos (o lo que es igual, sus intereses patrimoniales) en manos de personas de confianza, en aquellos que como los mercaderes conocían la sazón del tráfico mercantil o eran especialistas en justicia.

Quienes se presentaban ante los magistrados de la Contratación para resolver causas sobre cuentas eran esencialmente copropietarios de embarcaciones interesados en repartir los gastos y provechos de un navío en común, así como dueños de barcos que reclamaban la cuenta de un viaje en específico a los maestres con quienes estaban asociados. Al tribunal acudían tanto nacionales como extranjeros a resolver sus causas, fuera en esta materia o en cualquier otra, sin que existiera ningún prurito aparente respecto de la nación de origen de los litigantes. En este sentido, la consideración de Antonio Miguel Bernal consistente en que el arbitraje contable fue una práctica preferida por las comunidades extranjeras de Sevilla, cuyos miembros optaban por resolver sus conflictos al interno de su comunidad recurriendo al arbitraje entre connacionales para evitar la intromisión de la justicia ordinaria en sus negocios ${ }^{53}$, parece inexacta.

El arbitraje contable fue una práctica ampliamente extendida entre los tratantes de la Carrera de Indias, independientemente de su naturaleza o extranjería de los Reinos de Castilla ${ }^{54}$. Tampoco parece imprescindible que los

51 Esteban, 1999: 121-126.

52 Como consta en los autos iniciados por Antonio de Villalpando, donde figuran como contadores los abogados Diego de Andino y Lucas de Antezana, éste último nombrado de oficio el 2 de julio de 1590. Autos de Cristóbal de Santana Pareja, dueño de la tercera parte de una nao, con Antonio de Villalpando y Pedro de la Cal, dueños de las otras dos partes, sobre la cuenta del navio, año 1590, AGI, Contratación, legajo 731 B, exp. 28, s/f.

53 Bernal, 2008: 513-539.

54 Herzog, 2003: 64-118. Oliva, 2006: 400-416. García-Baquero, 2003, vol. I: 73-99. Bernal, 1992: 174-211. Konetzke, 1945: 269-299. Domínguez, 1960: 137-163. Vila, 2005: 279-296. Gil-Bermejo, 1989: 175-186. 
árbitros fueran connacionales; de hecho, claramente mercaderes castellanos confiaban sus cuentas a extranjeros y viceversa, ya no sólo al milanés Ferrofino sino a cualquiera que detentara las calidades profesionales suficientes para realizar el trabajo ${ }^{55}$.

La coacción que las decisiones de los magistrados de la Audiencia de la Contratación podían ejercer sobre los pleiteantes no sólo los orillaba a avenirse sino que, además, agilizaba la solución del problema disponiendo para ello de un plantel de expertos a su disposición. Tales beneficios no fueron despreciados por los pleiteantes, quienes no dudaban en echar mano de la potestad jurisdiccional de la Casa para resolver sus disputas y rehabilitar sus tratos. Así, en diciembre de 1592 dos genoveses, Julio de Negrón y Julio Briñali, siguieron un pleito en la Casa con motivo de las cuentas de la nao San Francisco de que eran dueños por mitad. Ambos mercaderes estaban naturalizados, Briñali56 residía en Nombre de Dios, mientras que Negrón ${ }^{57}$ radicaba en Sevilla. El primero, por vía de su apoderado, demandó al segundo el pago de los aprovechamientos del último viaje que el navío había hecho a la provincia de Honduras, solicitando a los jueces que obligaran a su socio a hacer la cuenta de la nao y que embargaran tanto el navío como sus provechos hasta que se realizaran las cuentas. El mismo día en que fue presentada la demanda los jueces decretaron el embargo del navío ${ }^{58}$.

55 Bartolomé de Grimaldo, genovés, fue nombrado por Juan Antonio y Francisca de Tovar como tercero contador que representara sus intereses en la elaboración de la cuenta de la urca el Cazador, después del requerimiento que para ello hicieron los jueces de la Casa el 2 de septiembre de 1589. Autos de Juan Antonio y Francisca de Tovar, dueños de la urca el Cazador, con el maestre Hernando Barbosa, sobre las cuentas de la urca, año 1589, AGI, Contratación, legajo 730 A, exp. 7, s/f. Lo mismo ocurrió con el portugués Francisco de Correa, quien decidió nombrar al flamenco Francisco de Cornelis para elaborar las cuentas del maestraje de la nao Nuestra Señora del Hospital, después del requerimiento que le hicieron los jueces de la Casa el 19 de noviembre de 1583. Autos de Vasco Rodríguez, dueño y capitán de nao, con Francisco Correa, su maestre, sobre las cuentas de su maestraje, año 1583, AGI, Contratación, legajo 724, exp. 9, s/f.

56 Por sentencia de revisa emitida por los consejeros de Indias el 7 de febrero de 1586, Julio Briñali obtuvo carta de naturaleza para tratar directamente en las Indias. Autos de Julio Briñali, vecino de Sevilla, con el fiscal, sobre naturaleza, año 1585, AGI, Escribanía, legajo 1069 B, f. 23.

57 Julio Negrón consiguió la licencia para tratar en Indias por sus factores en virtud de la sentencia de vista del Consejo de Indias dada el 12 de julio de 1585. Autos de Julio Negrón con el fiscal sobre naturaleza, año 1584, AGI, Escribanía, legajo 1069 A, f. 18r.

58 Orden de embargo decretada el 12 de diciembre de 1592. Autos de Alejandro Marín, apoderado de Julio Briñali, genovés, dueño de una parte de nao, con Julio de Negrón, genovés, dueño de la otra parte, sobre cuenta de dicha nao, año 1592, AGI, Contratación, legajo 733, exp. 5, s/f. 
Si bien el proceso quedó inconcluso, es notable que su último movimiento fue la orden de embargo del navío. Es posible que después de la presión ejercida por los oficiales de la Casa, una vez resguardado el objeto de la litis, las partes hayan conseguido un acuerdo fuera de la institución. Llama la atención que buena parte de los procesos sobre cuentas de compañías quedaron pendientes en la audiencia. Dicha deserción no tuvo que ver con la inoperancia o incompetencia del tribunal, sino con el abandono de la causa por los propios litigantes. En algunos casos las partes expresamente se desistieron del proceso por haber conseguido un acuerdo extrajudicial ${ }^{59}$; en otros casos las circunstancias en que se desarrolló el pleito, como el parentesco entre los pleiteantes o la inminencia de los últimos movimientos del proceso (dígase la amenaza con pena de prisión a una de las partes para que entregue la documentación al contador ${ }^{60}$ ), fortalecen la presunción de un acuerdo extrajudicial entre los oponentes. En este sentido, el objeto con el cual los litigantes se acercaban a los jueces de la Casa, lograr un acuerdo, quedaba satisfecho.

\section{CONCLUSIONES}

Queda claro que la realidad de los tratos ultramarinos precisó de soluciones jurídicas capaces de hacer cumplir los acuerdos comerciales de forma expedita y a bajo costo incluso a larga distancia. El arbitraje fue una de esas soluciones, aunque no fue un recurso infalible ni de eficacia generalizada. El principal problema del arbitraje era que los árbitros eran incapaces en la práctica de hacer cumplir sus sentencias, pues en muchos casos los litigantes desfavoreci-

59 Así concluyeron los siguientes procesos: Autos de Vasco Rodríguez, dueño y capitán de nao, con Francisco Correa, su maestre, sobre las cuentas de su maestraje, año 1583, AGI, Contratación, legajo 724, exp. 9; autos de Alonso de Avendaño, vecino de Sevilla, con Gabriel Meléndez, dueño de una cuarta parte de un navio, sobre cobranza de ella, año 1589, AGI, Contratación, legajo 730 B, exp. 15; autos del capitán Pedro de Arce, vecino de Laredo y residente en Sevilla, con Pedro de la Helguera y Luis de Rivas, maestres, vecinos de Sevilla y compañeros de cargazón de esclavos, sobre que le sacasen en paz y a salvo de una fianza que dio por todos, para cobranza de una partida procedente de dicha cargazón, año 1593, AGI, Contratación, legajo 736 B, exp. 31; y autos iniciados por Juan de Arrivillaga, como heredero de su tío, Esteban de Arrivillaga, con Juanes de Ayete, maestre de nao, sobre la cuenta de ella, que compraron por mitad, año 1595, AGI, Contratación, legajo 740, exp. 3.

${ }^{60}$ El 25 de julio de 1592, Bartolomé Arquero pidió a los jueces que pusieran preso a Luis Marco por no quererle presentar los documentos para hacer las cuentas. Autos de Luis Marco de Reinoso, vecino de Sevilla, con Bartolomé de Arquero y María Arquero, su hija, sobre la cuenta de la nao Santa Ana de que eran dueños por mitad, año 1592, AGI, Contratación, legajo 734 , exp. 4 , s/f. 
dos por el laudo continuaban el pleito en otras jurisdicciones buscando con ello obtener una sentencia beneficiosa para sus intereses. Este problema daba lugar a que los litigantes acudieran a los tribunales para que obligaran coercitivamente a las partes a cumplir las disposiciones de los árbitros.

Las fuentes evidencian cómo los litigantes acudían a tribunales como la Casa de la Contratación para demandar el cumplimiento del laudo gracias al carácter ejecutivo que la corona había atribuido a este tipo de sentencias desde mediados del siglo XVI, con la intención de remediar las limitaciones potestativas de los árbitros. Asimismo, se observa el recurso de los pleiteantes al tribunal para demandar la gestión de un arbitraje que debía desarrollarse concomitantemente a un proceso formal a través del cual se contuvieran los intentos de las partes por eludir el laudo o retrasar el desenlace del juicio arbitral. Los magistrados castellanos, por estar impedidos legalmente para servir como árbitros de los litigantes en su jurisdicción, eran requeridos por éstos para ocuparse del seguimiento del arbitraje a través de un juicio formalmente iniciado en la Casa. En dicho pleito los jueces delegaban la resolución de fondo del conflicto a los árbitros, limitándose a ejecutar el laudo o simplemente a presionar a los litigantes cuando intentaban obstaculizar el desarrollo de procedimiento arbitral. Esta práctica fue muy habitual, por ejemplo, en los pleitos relacionados con la contabilidad de las compañías entre mercaderes.

La Casa de la Contratación dispuso de la estructura material y humana necesaria para lograr el cumplimiento de las sentencias, sirviendo asimismo para suplir las limitaciones potestativas de otras justicias como los árbitros. Dicha infraestructura, así como el proceso judicial sumario previsto por el ordenamiento real castellano (el juicio ejecutivo) contribuyeron a optimizar la labor de tribunales reales de administrar justicia y colocó a las instituciones del rey en una posición altamente atractiva para los mercaderes litigantes, quienes se presentaban en ellas a litigar, pese a su falta de especialización en los asuntos del comercio.

\section{BIBLIOGRAFÍA}

Ago, Renata, Economia Barocca. Mercato e Istituzioni nella Roma del Seicento, Roma, Donzelli Editore, 1998.

Alonso Romero, María Paz y Garriga Acosta, Carlos, El régimen jurídico de la abogacía en Castilla (siglos XIII-XVIII), Madrid, Universidad Carlos III, 2013.

Aznar Vallejo, Eduardo, «El mar: fuente de conflictos y exigencia de paz», Edad Media Revista de Historia, 11 (Valladolid, 2010): 63-89. 
Baker, J. H., «The Law Merchant and the Common Law before 1700», The Cambridge Law Journal, 38/2 (Cambridge, noviembre 1979): 295-322.

Barrera Osorio, Antonio, Experiencing nature: the Spanish American Empire and the early scientific revolution, Texas, University of Texas Press, 2006.

Bernal, Antonio Miguel, La financiación de la Carrera de Indias (1492-1824). Dinero y crédito en el comercio colonial español con América, Sevilla, Fundación el Monte, 1992.

Bernal, Antonio Miguel, «La contabilidad como instrumento de conciliación y arbitraje en la Carrera de Indias (siglos XV-XVIII)», Anuario de Estudios Atlánticos, 54/1 (Madrid-Las Palmas, 2008): 513-539.

Cañizares-Esguerra, Jorge, Nature, Empire and Nation. Explorations of the History of Science in the Iberian World, Stanford, Stanford University Press, 2006.

Caunedo del Potro, Betsabé, "Mercaderes castellanos: algunos aspectos de su formación teórica», Juan A. Bonachía Hernando y David Carvajal de la Vega (eds.), Los negocios del hombre. Comercio y rentas en Castilla (siglos XV y XVI), Valladolid, Castilla Ediciones, 2012: 37-51.

Cervera Pery, José, La Casa de la Contratación y el Consejo de Indias (las razones de un superministerio), Madrid, Ministerio de Defensa, 1997.

Cordes, Albrecht, «The search for a medieval Lex mercatoria», Vito Piergiovanni (ed.), From lex mercatoria to commercial law, Berlin, Duncker \& Humblot, 2005: 53-67.

Coronas González, Santos M., Derecho Mercantil Castellano. Dos Estudios Históricos, León, Colegio Universitario de León, 1979.

Coronas González, Santos M., «La jurisdicción mercantil de los consulados del mar en el Antiguo Régimen (1494-1808)», Floriano Ballesteros Caballero, Hilario Casado Alonso, Alberto C. Ibáñez Pérez y Segundo Escolar Díez (eds.), Simposio Internacional «El Consulado de Burgos», Burgos, Publicaciones del V centenario del Consulado de Burgos, 1994: 251-279.

Cruz Barney, Óscar, «El arbitraje en México: notas en torno a sus antecedentes históricos», Ars Iuris, 24 (Ciudad de México, 2000): 53-110.

Domínguez Ortiz, Antonio, Los extranjeros en la vida española durante el siglo XVII, Madrid, Consejo Superior de Investigaciones Científicas, 1960.

Donahue, Charles, «Benvennuto Stracca's De Mercatura: Was There a Lex Mercatoria in Sixteentn-Century Italy?», Vito Piergiovanni (ed.), From Lex Mercatoria to Commercial Law, Berlin, Duncker \& Humblot, 2005: 69-120.

D’Ors, Álvaro, «Principios para una teoría realista del derecho», Anuario de Filosofía del Derecho (Madrid, 1953): 5-34. 
Dyson, Matthew e Ibbetson, David (eds.), Law and Legal Process. Substantive Law and Procedure in English Legal History, Cambridge, Cambridge University Press, 2013.

Esteban Piñeiro, Mariano, «La Academia de Matemáticas de Madrid», Enrique Martínez Ruiz (dir.), Felipe II: la ciencia y la técnica, Madrid, Actas editorial, 1999: 113-132.

Estepa Moriana, Vidal, «El juicio ejecutivo como proceso de ejecución en el derecho histórico español», Revista de Derecho Procesal Iberoamericana, 1 (Madrid, 1977): 87-101.

Fairén Guillén, Víctor, Lo «sumario» y lo "plenario» en los procesos civiles y mercantiles españoles: pasado y presente, Madrid, Colegio de Registradores de la Propiedad y Mercantiles de España, 2006.

Frankot, Edda, «Medieval Maritime Law from Oléron to Wisby: Jurisdictions in the Law of the Sea», Juan Pan-Montojo y Frederik Pedersen (eds.), Communities in European History: Representations, Jurisdictions, Conflicts, Pisa, Edizioni Plus Pisa University Press, 2007: 151-172.

García-Baquero González, Antonio, «Los extranjeros en el tráfico con Indias: Entre el rechazo legal y la tolerancia funcional», M. B. Villar García y P. Pezzi Cristóbal (eds.), Los extranjeros en la España moderna. Actas del I coloquio internacional celebrado en Málaga del 28 al 30 de noviembre de 2002, Málaga, 2003: 73-99, vol. I.

Garnot, Benoît (dir.), L'infrajudiciaire du Moyen Age à l'époque contemporaine, Bourgogne, Editions Universitaires de Dijon, 1996.

Gelderblom, Oscar, Cities of Commerce. The Institutional Foundations of International Trade in the Low Countries, 1250-1650, Princeton/Oxford, Princeton University Press, 2013.

Gil-Bermejo García, Juana, «Naturalizaciones de italianos en Andalucía», Bibiano Torres Ramírez y José J. Hernández Palomo (coords.), Presencia italiana en Andalucía (Siglos XIV-XVII). Actas del I Coloquio Hispano-Italiano, Sevilla, Escuela de Estudios Hispanoamericanos, 1989: 175-186.

Greif, Avner, «Contracting, enforcement, and efficiency: economics beyond the law», Michael Bruno y Boris Pleskovic (eds.), Annual World Bank Conference on Development Economics, Washington DC, The Wold Bank, 1997: 239-266.

Heredia Herrera, Antonia, «Las ordenanzas del Consulado de Sevilla», Archivo Hispalense, 171-173 (Sevilla, 1973): 149-183.

Herzog, Tamar, Defining nations. Immigrants and citizens in Early Modern Spain and Spanish America, New Haven/London, Yale University Press, 2003.

Jeannin, Pierre, «Distinction de compétences et niveaux de qualification: les savoirs négociants dans l'Europe moderne», Franco Angiolini y Daniel Roche (eds.), 
Cultures et formations négociants dans l'Europe moderne, Paris, EHESS, 1995: 363-397.

Kadens, Emily, «Order within Law, Variety within Custom: The Character of the Medieval Merchant Law», Chicago Journal of International Law, 5/1 (Chicago, 2004): 39-65.

Konetzke, Richard, «Legislación sobre inmigración de extranjeros en América durante la época colonial», Revista Internacional de Sociología, 3/11-12 (Madrid, julio-diciembre 1945): 269-299.

Kuehn, Thomas, Law, Family \& Women: Toward a Legal Anthropology of Reinaissance Italy, Chicago, University of Chicago Press, 1991.

Lamikiz, Xabier, Trade and Trust in the Eighteenth-Century Atlantic World. Spanish Merchants and their Overseas Networks, Woodbridge, Great Britain, Boydell Press, 2010.

Laviana Cuetos, María Luisa, «La organización de la Carrera de Indias, o la obsesión del monopolio», Revista de Historia Naval, 52 (Madrid, 2006): 19-35.

Lorenzo Sanz, Eufemio, «La requisición de las remesas de oro y plata de mercaderes y particulares por la corona en el siglo XVI», Anuario de Estudios Americanos, 34 (Sevilla, 1977): 271-293.

Lumbreras Valiente, Pedro, «Aportación a la historia del juicio ejecutivo en el derecho patrio», Revista de Derecho Procesal, 2 (Madrid, 1960): 243-252.

Maccioni, Elena y Tognetti, Sergio (eds.), Tribunali di mercanti e giustizia mercantile nel tardo medioevo, Firenze, Casa Editrice Leo S., 2016.

Martínez Gijón, José, La compañía mercantil en Castilla hasta las ordenanzas del Consulado de Bilbao de 1737. Legislación y doctrina, Sevilla, Publicaciones de la Universidad de Sevilla, 1979.

Martiré, Eduardo, «El marco jurídico del tráfico con las Indias españolas», Carlos Petit (ed.), Del Ius Mercatorum al Derecho Mercantil. III Seminario de Historia del Derecho Privado (Sitges, 28-30 de mayo de 1992), Madrid, Marcial Pons, 1997: 229-235.

Martone, Luciano, Arbiter-Arbitrator. Forme i giustizia privata nell' età del diritto comune, Napoli, Casa Editrice Jovene, 1984.

Merchan Álvarez, Antonio, El arbitraje. Estudio histórico jurídico, Sevilla, Publicaciones de la Universidad de Sevilla, 1981.

Miller, William Ian, «Avoiding Legal Judgment: The Submission of Disputes to Arbitration in Medieval Iceland», The American Journal of Legal History, 28/2 (Philadelphia, abril 1984): 95-134.

Montero Aroca, Juan, La herencia procesal española, México, UNAM, 1994. 
Ogilvie, Sheilagh, Institutions and European Trade. Merchant Guilds (1000-1800), Cambridge, Cambridge University Press, 2011.

Oliva Melgar, José María, «Naturales y extranjeros en el negocio de Indias y en la inversión productiva en Andalucía (siglo XVII)», Carmen Sanz Ayán y Bernardo José García García (coords.), Banca, Crédito y Capital. La Monarquía Hispánica y los antiguos Países Bajos (1505-1700), Madrid, Edición para la Fundación Carlos de Amberes, 2006.

Pérez-Mallaína Bueno, Pablo E., El hombre frente al mar: naufragios en la Carrera de Indias durante los siglos XVI y XVII, Sevilla, Universidad de Sevilla, 1996.

Petit, Carlos, «Casa y Tribunal. Jurisdicción y conflictos de la contratación en sus años fundacionales», Guiomar de Carlos Boutet (ed.), España y América. Un océano de negocios: Quinto centenario de la Casa de la Contratación (15032003), Madrid, Sociedad Estatal de Conmemoraciones Culturales, 2003: 119-130.

Petit, Carlos, «Del usus mercatorum al uso de comercio. Notas y textos sobre la costumbre mercantil», Revista da Facultade de Direito, UFPR, 48 (Curitiba, 2008): 7-38.

Petit, Carlos, «Mercatura y Ius Mercatorum, Materiales para una antropología del comerciante premoderno», Carlos Petit (ed.), Del ius mercatorum al derecho mercantil: III seminario de Historia del Derecho Privado, Sitges, Marcial Pons, 1997: 15-70.

Real Díaz, José Joaquín, «El Consulado de cargadores a Indias: su documento fundacional», Archivo Hispalense, 147-152 (Sevilla, 1968): 279-291.

Royo Pérez, Vicent, «El arbitraje en la documentación medieval valenciana. La caracterización de la institución arbitral en la práctica documental de las comarcas de Els Ports y El Maestrat entre 1232 y 1412», Anuario de Historia del Derecho Español, LXXXVI (Madrid, 2016): 141-195.

Ruiz Rivera, Julián y García Bernal, M. C., Cargadores a Indias, Madrid, Mapfre, 1992.

Sardone, Sergio, «Los secuestros de las remesas americanas de particulares de Carlos V a través de los notarios sevillanos», Temas Americanistas, 29 (Sevilla, 2012): 21-64.

Schäfer, Ernesto, El Consejo Real y Supremo de las Indias. Historia y organización del Consejo y de la Casa de Contratación de las Indias, Madrid, Marcial Pons, 2003, tomo I.

Trueba, Eduardo, Sevilla: Tribunal de océanos (siglo XVI), Sevilla, Gráficas del Sur, 1988.

Valiño Arcos, Alejandro, Del arbitraje en els Furs de València y sus similitudes con la regulación romana, Valencia, Ajuntament de València, 2002.

Vallejo, Jesús, «Amor de árbitros. Episodio de la sucesión de Per Afán de Ribera el Viejo», Johannes-Michael Scholz (coord.), Fallstudien zur Spanichen und Portu- 
giesischen Justiz 15. Bis 20, Jahrhundert, Frankfurt am Main, Klostermann, 1994: 211-269.

Vas Mingo, Martha Milagros del, «La Justicia Mercantil en la Casa de la Contratación de Sevilla en el siglo XVI», Estudios de Historia Novohispana, 31 (Ciudad de México, julio-diciembre 2004): 73-97.

Vila Vilar, Enriqueta, «Los Europeos en el Comercio Americano: Sevilla como Plataforma», Renate Pieper y Peer Schmidt (eds.), Latin America and the Atlantic world (1500-1850). Essays in honor of Horst Pietschmann, Köln/Weimar/Wien, Böhlau Verlag, 2005: 279-296.

Volckart, Oliver y Mangels, Antje, "Are the Roots of the Modern Lex Mercatoria Really Medieval?», Southern Economic Journal, 65/3 (Richmond, enero1999): 427-450.

White, Stephen D., «Pactum... Legem Vincit et Amor Judicium. The Settlement of Disputes by Compromise in Eleventh-Century Western France», The American Journal of Legal History, 22/4 (Philadelphia, octubre 1978): 281-308.

Wolaver, Earl S., «The historical background of commercial arbitration», The University of Pennsylvania Law Review and American Law Register, 83/2 (Pennsylvania, diciembre 1934): 132-146.

Fecha de recepción: 6 de febrero de 2017.

Fecha de envío de las modificaciones: 3 de marzo de 2017.

Fecha de aceptación: 7 de marzo de 2017.

\section{Eschewing courts? Commercial litigation and the practice of arbitration in the Carrera de Indias during the sixteenth century}

Arbitration has traditionally been considered as the ideal way to settle commercial disputes. However, the court records of the House of Trade of Seville show the difficulties this form of resolution faced in practice. Arbiters required the intervention of formal courts to get their decisions enforced, which distorted the purpose of arbitration as an extrajudicial, simplified and low cost solution.

Key words: Arbitration; House of Trade; Commercial Litigation; Ordinary Justice; Long Distance Trade. 